\title{
Os hospices e os programas de voluntariado para o câncer
}

\author{
Hospices and volunteer cancer programs
}

Entrevista com/Interview with Marcos M oraes

Concedida a/Interview given to Claudia Jurberg

Jornalista, Instituto Oswaldo Cruz/ Fiocruz e Instituto de Bioquímica Médica/UFRJ

cjurberg@bioqmed.ufrj.br

JaimeL. Benchimol

Luiz Antonio Teixeira

Pesquisadores da Casa de Oswaldo Cruz/Fiocruz

jben@coc.fiocruz.br

teixeira@ coc.fiocruz.br

\section{Ruth B. Martins}

Jornalista, Casa de Oswaldo Cruz/ Fiocruz

rmartins@coc.fiocruz.br
MORAES, Marcos. Os hospices e os programas de voluntariado para o câncer. Entrevista concedida a Claudia Jurberg, Jaime L. Benchimol, Luiz Antonio Teixeira e Ruth B. Martins. História, Ciências, Saúde Manguinhos, Rio de Janeiro, v.17, supl.1, jul. 2010, p.203-221.

\section{Resumo}

Entrevista com o cirurgião Marcos Fernando de Oliveira Moraes, presidente da Fundação do Câncer no Rio de Janeiro, entidade privada que apóia pesquisas e ações de controle da doença e funciona em parceria com o Instituto Nacional do Câncer, do qual foi diretor-geral. Narra suas atividades de médico e gestor, aborda a importância da prevenção e do diagnóstico precoce e apresenta dados sobre a mudança de hábitos, como o de fumar em público. Enfatiza a recente organização do primeiro hospice na cidade, "um lugar para onde as pessoas vão para aproveitar da melhor maneira possível o resto de vida que têm". Atenta para a importância dos programas de voluntariado, fundamentais para o tratamento mais humanizado da doença.

Palavras-chave: Marcos Fernando de Oliveira Moraes; Fundação do Câncer no Rio de Janeiro; Instituto Nacional do Câncer; trabalho voluntário e câncer; hospice.

\section{Abstract}

Interview with the surgeon Marcos Fernando de Oliveira M oraes, chairman of Rio deJaneiro's Cancer Foundation, a private organization that provides support for cancer research and control initiatives, in partnership with theN ational Cancer Institute (Instituto Nacional do Câncer, or Inca), of which M oraes was director general. Dr. Moraes narrates his activities as a physician and administrator, addresses theimportance of prevention and early diagnosis, and presents data on changing habits, like smoking in public. He highlights the recent creation of the city's first hospice, "a place where people go to spend the remainder of their lives as well as they can." Hestresses the importance of volunteer programs, which are essential to providing more humanized treatment.

Keywords: Marcos Fernando de Oliveira M oraes; Rio deJaneiro Cancer Foundation; National Cancer Institute; volunteerism and cancer; hospice. 
São múltiplas as frentes com que o cirurgião Marcos Fernando de Oliveira Moraes lida Sno universo da oncologia, seja como médico, seja como gestor de instituições nesse campo da saúde. Nesta entrevista el e conta histórias sobre a luta incessante contra o câncer travada por doentes, médicos, seus familiares e os voluntários dos programas que o combatem.

Marcos Moraes preside o Conselho de Curadores da Fundação do Câncer, instituição privada que apoia a pesquisa e as ações de controle da doença, e que também visa angariar recursos, funcionando em parceria com o Instituto Nacional do Câncer, de onde ele foi diretor-geral entre 1990 e 1998.

Ultimamente, o alagoano de Palmeira dos Índios vem-se dedicando à organização do primeiro hospice na cidade, "um lugar para onde as pessoas vão para aproveitar da melhor maneira possível o resto de vida que têm". Ele conta que já obtiveram parte dos recursos necessários para sua implantação: "O lugar deve ser bonito. Tem que ter plantas, flores", acentua.

Foi tão forte o envolvimento de Marcos Moraes com uma paciente terminal, que a fez personagem de um conto seu, "Marta". Sua história: a pobre mulher protelou por dois anos a ida ao médico, depois de descobrir um nódulo no seio. Sua ideia era evitar a perda do emprego de doméstica, no Flamengo. Ela tinha quatro filhos: Paula, deficiente física; João, querido pela vizinhança, no bairro do Caju onde moravam, tinha um problema grave - bebia demais; Maria era prostituta e Cida, telefonista. Quando Marta foi atendida no Hospital de Ipanema, já não havia o que fazer. Dali, foi transferida para a Casa de Repouso, que abriga pacientes sem possibilidade de cura.

Tempos depois, apreensiva, voltou para casa quando soube que seus filhos estavam dispostos a participar de um programa supervisionado pelo Inca. João e Maria foram treinados e cuidaram da mãe durante 47 dias. Doutor Marcos conta que esteve duas vezes com Marta, quando vivenciou momentos gratificantes. Finaliza assim sua história:

Durante as visitas, chorando de felicidade, ela dizia que estava vivendo os dias mais importantes de sua vida. Seusfil hos João e Maria, por quem tin ha grande preocupação, agora eram pessoas amorosas e capazes de demonstrar amor ecarinho. M orreu fel iz.

Mesmo percebendo que o trabalho voluntário ainda é incipiente em nosso país, o médico é otimista e acredita no aumento do número de pessoas a se interessar por essa forma de participação. Como exemplo desse potencial, ele descreve um 'hotel' no Rio, parceria do Inca com o McDonald's, que dispõe de 65 leitos para crianças em tratamento de rádio e quimioterapia e conta com 400 funcionários, dos quais apenas um tem remuneração: "a humanidade tem um potencial enorme de doar ao próximo ... precisa ser estimulada para isso".

Trabalhos tecnocientíficos e estatísticas sobre a incidência da doença revelam cenário difícil. No texto em que apresenta as estimativas para o Brasil em 2010, o diretor-geral do Instituto Nacional do Câncer, Luiz Antonio Santini, destaca que, desde 2003, a doença é a segunda causa de mortes no país, alcançando índices de quase 17\%. Perde apenas para as cardiovasculares. Segundo o especialista, "câncer é termo utilizado genericamente para representar mais de cem doenças, incluindo tumores malignos de diferentes localizações". 
Em âmbito global, as taxas de mortalidade também assustam: o World Cancer Report de 2008, relatório da Agência Internacional para Pesquisa sobre o Câncer da Organização Mundial de Saúde (Iarc/OMS), registra que nos últimos 30 anos os índices de incidência da doença mais do que duplicaram. A estimativa da larc naquele ano era a de que seriam contabilizados algo em torno de 12,4 milhões de casos novos de câncer, e a doença provocaria aproximadamente 7,6 milhões de óbitos. Com o envelhecimento e o contínuo crescimento populacional, a expectativa é de que o maior impacto do câncer recairá sobre os países de médio e baixo desenvolvimento. Ainda segundo a mesma agência, metade dos casos novos e cerca de 2/3 das mortes por câncer ocorrerão nessas regiões.

Desse total de casos contabilizados, o câncer de pulmão atingiu 1,52 milhão de casos novos; o de mama afetou 1,29 milhão de mulheres; e os casos de câncer de cólon e reto chegaram a somar 1,15 milhão. O câncer de pulmão também foi o vilão em número de mortes, fazendo 1,31 milhão de vítimas, seguido pelo câncer de estômago, com 780 mil óbitos, e o câncer de fígado, com outras 699 mil mortes. Para a América do Sul, Central e Caribe, a agência da OMS previa, em 2008, aproximadamente um milhão de casos novos de câncer e 589 mil óbitos.

No Brasil, ainda segundo essas mesmas estimativas para o ano de 2010, a expectativa é de que ocorram 489.270 casos novos de câncer. Os tipos mais incidentes, à exceção do câncer de pele do tipo não melanoma, serão os cânceres de próstata e de pulmão, no sexo masculino, e os cânceres de mama e de colo do útero, no sexo feminino.

No artigo "Forty years' war: advances elusive in the drive to cure cancer", veiculado no The New York Times em 23 de abril de 2009, a jornalista Gina Kolata apresenta sombria síntese sobre a situação da doença nos EUA. Ela destaca que a doença passou a ser uma "prioridade cara" para o país quando o presidente Richard Nixon anunciou que tinha como objetivo a cura do câncer até 1976: "o ano chegou e se foi, e a data para uma cura, ou pelo menos algum progresso substancial, continuou sendo postergada. Aconteceria em 2000, depois em 2015. Agora, ... Barack Obama ... prometeu encontrar 'uma cura' para o câncer em nosso tempo" - ironiza.

Segun do a repórter, a maior instituição pública de pesquisa dos EUA, o National Institute of Cancer, com quatro mil funcionários, naquela data já havia gasto 105 bilhões de dólares. Fora os "incontáveis bilhões" despendidos por outras agências públicas e filantrópicas, universidades, indústria farmacêutica. E, mesmo assim, as taxas de mortalidade pela doença nos Estados Unidos caíram apenas 5\% entre 1950 e 2005. Verifique o contraste entre a redução do número de mortes por outros males no mesmo período: as taxas de mortalidade provocadas por doenças cardiovasculares caíram $64 \%$, e por gripe e pneumonia a queda atingiu $58 \%$.

No que diz respeito à prevenção, os avanços ainda são lentos, ressalta Gina Kolata. "Apenas algumas coisas - parar de fumar, por exemplo - fazem diferença. Dietas ricas em fibras, baixas em gordura ... fracassaram em encontrar um efeito". No entanto, o artigo traz algumas boas novas para quem tem o diagnóstico precoce e pode viver alguns anos com qualidade.

E foi exatamente isso - qualidade- queo médico Marcos Moraes diz ter buscado implantar durante sua gestão no Inca, marcada pela forma moderna de administrar o hospital, 
visando ao conforto do doente. Ele envolveu os profissionais, que passaram a participar da implantação de um Programa de Gestão pela Qualidade Total, e logo a instituição tinha nova estrutura - passou a ser um departamento do Ministério da Saúde - e tornouse referência nacional para o controle do câncer no Brasil.

À entrevista!

Ruth B. Martins

\section{u u UUU}

Claudia Jurberg

Você poderia falar um pouco sobre o problema do câncer hoje no Brasil?

O cigarro é responsável por mais ou menos 30\% das mortes por câncer no mundo. Aqui no Brasil, mostramos, em 1994, em uma grande reportagem na revista Veja, que a Souza Cruz adicionava amônia à mistura do cigarro para liberar mais nicotina e aumentar a dependência. Acho que esse foi o primeiro grande impacto contra a credibilidade que até então os dirigentes dessas empresas possuíam. As companhias de cigarro utilizam muito as crianças e os adultos jovens para transformá-los em novos fumantes. Mostramos que a Souza Cruz não era a santa provedora, ajudando as universidades, atuando em outros setores da sociedade em que os jovens estavam. A partir daí, começamos a ganhar uma batalha que, no Brasil, era impossível. Era impossível imaginar que um dia o cigarro seria banido dos voos, de ambientes fechados e também que a propaganda fosse proibida. A luta era também contra a mídia, que devia, naquela época, grande parte de seu faturamento à indústria de fumo. As companhias investiram, por décadas a fio, na associação de cigarro ao glamour, à beleza, à maior capacidade física, ao maior desempenho nos esportes financiados. No cinema, especificamente nos filmes produzidos a partir dos anos 1940, mulheres e homens fumavam sem parar. Casablanca é um bom exemplo; como se fuma naquele filme! Muitos atores acabaram morrendo de câncer de pulmão, e Humprey Bogart foi um deles.

As companhias de cigarro desenvolveram centenas de estratégias ao longo do tempo. Uma delas foi criar mecanismos para tornar a adição da nicotina mais forte. Uma abordagem errada ainda é recorrente: infantilizar o fumante - "Se ele sabe que faz mal à saúde, por que não deixa de fumar?". Em vez dessa postura, devemos encaminhá-lo ao tratamento para dependência química, pois a relação de quem fuma com a doença já é estabelecida, e a dependência à nicotina é mais forte do que a qual quer outra droga. A ação contra o fumo ou contra o tabagismo tem várias frentes de combate: passa pelo indivíduo, pela indústria, mas, sem nenhuma dúvida, a coisa mais efetiva para a redução do consumo é taxar. Quanto mais caro o cigarro, menor o consumo. É diretamente proporcional. Nesse sentido, é fundamental a intervenção do Estado.

Como é essa briga com as indústrias? Sabe-se que, em relação à Convenção-Quadro para o Controle do Tabaco, ainda temos grandes problemas com os plantadores de fumo no Sul.

Estão mudando, graças ao papel de liderança da Organização Mundial da Saúde (OMS) e de reuniões como a Convenção-Quadro, que definem regras em relação à propaganda, à 
proteção do fumante passivo e a uma série de aspectos. E não é preciso análise científica. Todos nós percebemos, onde vivemos, que o cigarro em público diminuiu muito. Numa festa hoje, olhe a sua volta. As pessoas não se sentem bem fumando.

Mas temos que oferecer alguma alternativa para o sujeito que vive do plantio. E há várias opções no próprio local, no próprio plantio, de se aproveitar a terra de maneira muito mais lucrativa. Um bom exemplo acontece no Rio Grande do Sul, maior produtor brasileiro, na cidade de Santa Cruz do Sul, considerada a maior produtora de folha de fumo no mundo. Há mais de 15, 20 anos, a Arquidiocese e a Secretaria de Agricultura têm adotado estratégias para estimular o agricultor a sair do ramo. Ainda assim, essa indústria é muito forte e segue fazendo ofertas imediatas que fascinam e estimulam o agricultor a permanecer no cultivo do fumo. Quando analisamos documentos que antes eram secretos e hoje estão disponíveis em vários sites de organizações contra o fumo, vemos estratégias criadas para manter as pessoas plantando e para estimular o consumo de indivíduos cada vez mais jovens. É uma guerra.

Mas isso representa 30\%. E o que acontece com o resto? Como é o panorama do câncer no Brasil? Como podemos tratá-lo? A melhor forma é prevenir com mudanças nos hábitos de viver. A segunda melhor forma é diagnosticar precocemente. E para isso é preciso educar a população tanto leiga quanto médica e dar suporte adequado para que, aos primeiros sinais, o indivíduo seja examinado, mesmo que ele não tenha queixa, mesmo sem nenhum sinal, porque muitas vezes são doenças que aparecem em determinadas partes do organismo de maneira silenciosa. Exemplo do que já vem sendo feito é o trabalho de prevenção do câncer de colo do útero. Trata-se de programa a longo prazo, pelo qual os países mais desenvolvidos levaram 15, 20 anos para obter impacto sobre a mortalidade da população. Os países menos desenvolvidos ainda não estão organizados. A doença ainda mata muita gente no Brasil.

No Brasil, os índices aumentaram nos últimos anos, não?

Não digo que estejam ampliando, mas não estão diminuindo. Diferente do que ocorre com algumas doenças.

Para a preven ção de qual quer câncer, de colo, de próstata, todas as estratégias devem ser programadas. Você lê uma campanha: “Quando completar 50 anos, faça seu próprio exame de próstata". No interior do Nordeste já é um preconceito enorme o homem ser examinado e submeter-se ao toque retal. E então, com quem vai fazer? Onde vai? Principalmente em um país com a população como a nossa, com enorme carência em determinadas regiões. Essas são as barreiras que enfrentamos para ter um resultado melhor no tratamento do câncer.

Especificamente em relação ao câncer cervical (colo do útero), a OMS acredita que se a mulher for examinada pelo menos uma vez na vida, fizer o exame citológico e adotar a conduta adequada, a mortalidade por câncer de colo do útero será reduzida em $50 \%$. Quais são os empecilhos para você alcançar esse alvo? Primeiro, as mulheres recrutadas pela mídia, na maioria das vezes, são as que já fazem normalmente exame; são mais instruídas, têm mais acesso à informação. As que precisam ser atingidas, além de não 
estarem expostas à mídia do dia a dia, têm muito preconceito. São mulheres cujo marido não permite que elas façam um exame ginecológico, por motivos sociais, por dificuldades de locomoção, por acesso. O problema começa no recrutamento. Aqui no Inca, há alguns anos oferecemos o exame a mulheres de faixa etária e grupo social de maior risco. Quantas delas vieram pela mídia, pelas campanhas, espontaneamente? Em torno de $11 \%$. Eu digo na fase de prevenção primária, no exame anual. Se a propaganda é feita com uma mulher famosa, como a Cássia Kiss, por exemplo, dizendo que o exame ginecológico é importante, as mulheres pensam: "Eu não sou aquela mulher; eu sou feia, eu vivo em condições muito ruins de higiene...". Ela não se identifica com aquela imagem. Então, mais de $80 \%$ das mulheres não atendem a esse apelo. Essas mulheres são influenciadas pelos líderes locais, os visitadores sociais, ou pelas lideranças religiosas, por políticos... Líderes comunitários, de alguma forma, influenciam. Os amigos...

Na primeira etapa do recrutamento, você tem que preparar as pessoas. Na segunda parte, como será o exame? Depois de colher vai mandar para onde? O exame demanda, além da facilidade do kit, pessoas na comunidade, técnicos capazes de examinar com segurança. É preciso preparar os citotécnicos do país inteiro. Para que o exame seja feito com acurácia, é preciso que você tenha al guma maneira de checar a qualidade dos laudos desses citotécnicos. Faz-se necessária uma rede nacional. O resultado desse exame tem que chegar à mulher. E quando há um diagnóstico de advertência, onde essa mulher será tratada? Pois ela precisa de tratamento. Então tem-se que preparar a infraestrutura para, recebido o diagnóstico, a mulher ser encaminhada a algum lugar em que será tratada adequadamente. Na maioria das vezes, com o diagnóstico da doença inicial, o tratamento deve ser no ambulatório. A conização de colo do útero é procedimento extremamente simples, mas a paciente precisa ser acompanhada durante al guns anos. Essas etapas, porém, aparentemente muito simples, levaram 10, 15 anos nos países adiantados. No Brasil, fazemos um número de exames anuais que eu considero suficiente para cobrir a faixa etária de risco.

Como ocorre o controle do câncer cervical hoje? E as campanhas, são efetivas?

Como já comentei, campanhas não valem nada; é preciso um programa a longo prazo. Campanhas já tivemos quinhentas mil, e os índices não melhoraram. Ninguém faz milagre nesse campo.

\section{Existe um bom programa no Brasil hoje?}

Existe um grande programa nacional em processo de institucionalização. Quando começamos isso para valer, procuramos o melhor país do mundo, que possuía o melhor programa de prevenção ao câncer de colo de útero - o Canadá. Isso foi em 1995, 1996. Os técnicos vieram para cá e trabalharam conosco por quase dois anos. Chegamos a organizar cinco centros, em macrorregiões do país. Depois um ministro mudou, alegando que era muito lento. Ele acreditava que o ideal era fazer uma grande campanha, que o bom era fazer 30 milhões de exames por todo o país em dois meses. Não adianta. Campanhas não adiantam. Campanha de recrutamento adianta dentro de um programa de saúde já traçado. 
Depois de fazer os exames, vai fazer o quêcom eles? Nada. As mulheresjá estão acostumadas, coitadas, a fazer exames e depois, nada. Um diagnóstico precoce passa pela elaboração de programas permanentes.

É diferente do câncer de mama, que requer outra abordagem. Com relação ao de colo do útero, é possível, de maneira muito simples, cuidar das alterações prémalignas. Já com o câncer de mama é diferente: trata-se o tumor, mas não há como fazer sua prevenção. Trata-se a doença precoce.

E em relação a outros tipos de câncer?

O câncer é diferente de algumas doenças. Posso dar o exemplo das doenças cardiovasculares. Nos últimos 40 anos, a redução da mortalidade por doenças cardiovasculares foi maravilhosa. A redução da mortalidade por câncer nos últimos 40 anos é praticamente uma linha, se compararmos os 4\% do câncer em 50 anos aos 50\% de redução das doenças cardiovasculares. Espera-se quea mortal idade por câncer vá diminuir nos próximos decênios, nos países mais desenvolvidos e aumentar muito nos países menos desenvolvidos.

Observe o gráfico com o número de testes citológicos feitos no Brasil entre 1996 e 2006; veja como aumentou; agora olhe a curva da mortalidade pela doença.

Gráfico comparativo entre mortalidade por câncer do colo uterino e número de exames citopatológicos realizados entre 1996 e 2006
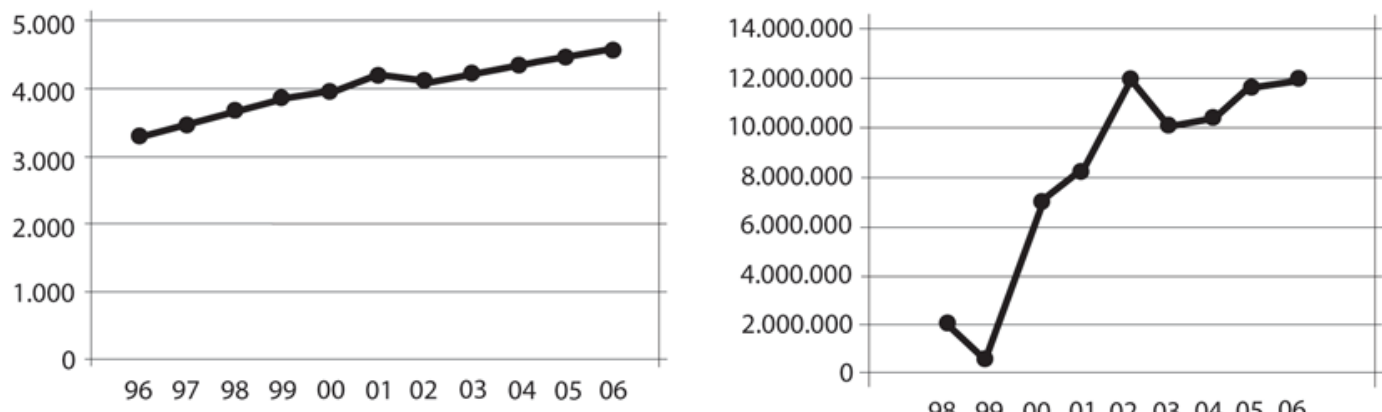

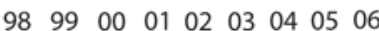

Fonte: Inca, 2010.

Isso por quê? Os testes não tiveram consequência?

Como falei, não adianta aumentar o número de exames e a curva de mortalidade continuar a mesma. Para que a ampliação dos testes tivesse a consequência desejada, teriam de vir conjugados, obrigatoriamente, o tratamento e o acompanhamento da paciente no longo prazo. Retornando ao cigarro, houve declínio do número de fumantes entre 1980 e 2004.

No caso do tabagismo, as campanhas funcionaram?

Não são campanhas, são programas permanentes, pesados. É mais simples do que o de colo do útero. O câncer provocado pelo cigarro está diretamente associado a deixar de fumar. 
O de colo do útero implica uma sucessão de etapas: você tem que recrutar, fazer um exame, acompanhar. Deixar de fumar é convencer o indivíduo sobre uma coisa que lhe fará mal. Não é difícil convencer uma mulher a fazer o exame; mas e depois? E o acompanhamento?

E o câncer de pulmão diminuiu?

Nos homens, a incidência está estabilizada, mas nas mulheres está aumentando, porque as mulheres, com a liberação feminina, passaram a fumar mais. No geral, porém, o aumento da população e da vida média dessa população como um todo faz com que a diminuição do número de cânceres não atinja a proporção esperada.

Gráfico comparativo da mortalidade por câncer de traqueia, brônquios e pulmões em homens e mulheres, ajustado por idade, pela população mundial, por 100.000, Brasil, entre 1996 e 2006

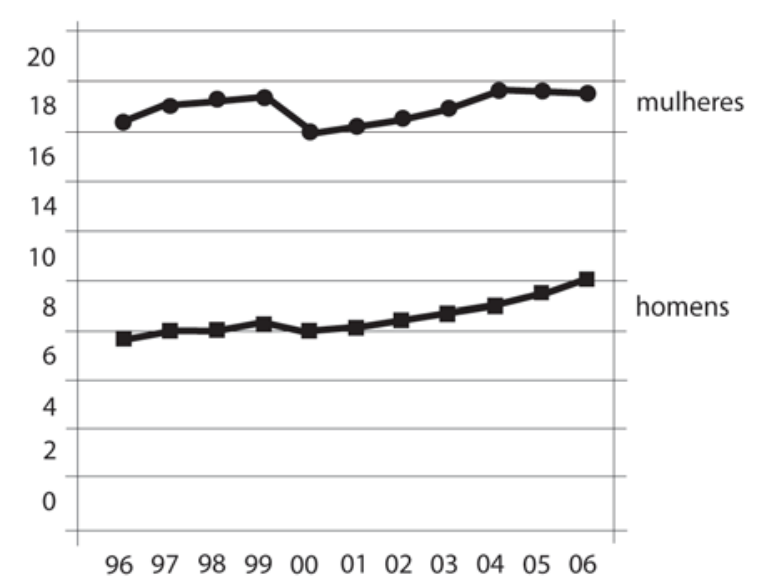

Fonte: Inca, 2010

Em relação ao tratamento da doença, o que existe de novo?

Gastou-se bastante em pesquisas, e muitas ainda estão em andamento. Mas temos um grande problema hoje no tratamento do câncer, que se relaciona às novas drogas com base em engenharia genética, biologia molecular. Descobriram a terapia-alvo, que trata diretamente as células doentes. São remédios extremamente caros, e o efeito na sobrevida do indivíduo, no prolongamento da vida e na qualidade de vida ainda é muito pequeno. A gente pode dar alguns exemplos, como o anticorpo monoclonal, que é utilizado para combater o câncer do intestino. O tratamento custa mais ou menos em torno de sete, oito mil dólares por mês, e o resultado global de aumento da sobrevida é em torno de um mês, para um tratamento de seis a oito meses.

Os transtornos sociais dessas terapias continuam iguais aos da quimioterapia?

Não. As drogas estão trazendo menos efeitos colaterais. O problema do consumo dessas drogas novas é a relação custo/benefício: $70 \%$ do que se consome globalmente no cuidado com o câncer, desde a prevenção até o tratamento, concentram-se nos últimos seis meses de vida. O que prova que a maioria dos tratamentos é feita em pessoas sem qualquer 
possibilidade de cura, mas que precisam ser tratadas para eliminar a dor, para melhorar a qualidade de vida, sem precisar receber os efeitos colaterais de medicações que são questionáveis. Há indivíduos que passaram por milagres, como Lance Armstrong, o sujeito que ganhou sete vezes o circuito de bicicleta da França. Ele teve um câncer que evoluiu mal, tomou uma dessas drogas e ficou bom. Deu sete voltas na França e ganhou as sete. Terá sido devido à droga? Pode ser. Mas esse é apenas um caso.

Questionam até se foi um milagre.

Como se pode provar se foi a droga ou não? Você pode provar se investigar mil indivíduos com doença idêntica e tiver bom resultado com um número razoável. Se comparar mil indivíduos que tomaram aquela droga com mil indivíduos que não tomaram, a mortalidade é mais ou menos a mesma. É muito pouco provável que se possa considerar aquela droga o único fator daquele milagre. Acontece que existem poucos estudos. Não é ceticismo, não é falta de esperança. Acontece que em qualquer país, do ponto de vista de política de Estado, é muito mais importante gastar nas outras etapas do que tratar um indivíduo só para evitar efeitos colaterais que ele não precisava ter no final de sua vida. O que é preciso fazer com as pessoas que têm um tumor não mais tratável? Há quem diga: "Não tem mais o que fazer" - mas há, sim, muito a fazer! Podemos oferecer tratamento com dignidade, respeito à pessoa, que deve ser atendida em seus diferentes sintomas, às demandas da doença. Dor é sintoma importantíssimo para o tratamento final do câncer. $O$ indivíduo tem que ter apoio. Aqui no Inca há um programa desenvolvido numa unidade para pacientes fora de possi bilidades terapêuticas com 60 leitos. Lá, as pessoas são tratadas e estimuladas a ir para casa, quando possível, a fim de ser tratadas pela família. Nós mandamos remédios, uma visita em casa, uma cesta básica para a família quando necessário. E essas pessoas certamente morrem com muito mais dignidade do que se estivessem sendo invadidas por remédios, tubos... Hoje, em todo o mundo, está surgindo essa prática. São os hospices, lugares para onde as pessoas vão no intuito de aproveitar da melhor maneira possível o resto de sua vida.

Às vezes, a pessoa entra em uma UTI e começa a ser invadida, sem ninguém explicar nem perguntar nada: um cateter na veia, um cateter na bexiga. Atacam o paciente de diversas formas, e ele não tem direito nem de saber o que está acontecendo. Então, o hospice é exatamente para evitar que isso aconteça, para ensinar à pessoa que, mesmo no curso daquela doença, é possível aproveitar seus últimos dias. Às vezes, você atende a pequenos desejos que são muito importantes para o paciente. São pequenos problemas; em alguns casos, o sujeito que está internado preocupa-se em pagar $\mathrm{R} \$ 300,00$ pelo barraco dele ao grileiro, senão o perde. São coisas pequenas.

Lembro-me da história de um garoto de 12 anos, com leucemia, que fez um transplante de medula e que era apaixonado pela Angélica. Ele já estava isolado, porque suas condições de saúde eram bastante precárias. Então disse à enfermeira que queria falar com o diretor. A moça da unidade chamou-me. O garoto me disse: "A Angélica vem aí, mas eu não posso vêla. Será que o senhor podia pedir para ela vir até aqui?". Eu pedi, e ela foi lá. Esse garoto viveu uns 20 dias. Ela foi visitá-lo outras vezes. É impressionante como esse garoto mudou nesses 20 dias. A filosofia do hospice começou na Inglaterra exatamente com a ideia, entre 
aspas, de 'ensinar a pessoa a morrer', de viver com dignidade o resto da vida que lhe cabe. Obter algum resultado com essa mudança de cultura exige um longo curso, não é?

Sim, para trabalhar nisso a pessoa tem que se preparar, ter vocação, sensibilidade. A partir do momento em que se assume o compromisso de tratar de uma pessoa dessas, tem-se que tratar da família; é preciso se comprometer, dar apoio às famílias depois da perda. É uma série de etapas que não podem ser quebradas, pois você invalida, desmoraliza sua ação.

\section{Esse programa é do Ministério da Saúde?}

É um programa novo do Inca. Quando o paciente tem família, pode-se convencêla. Mas há famílias que trabalham. A primeira unidade que fizemos, agora com dez anos de experiência, era focada no doente terminal, pois ele passa a ser um pária, mesmo no hospital do câncer, onde ele chega para ser reinternado pela décima vez e recebe um olhar de rejeição. Quando fizemos essa unidade em Vila Isabel, no Rio de Janeiro, visamos à dedicação exclusiva a esse paciente. Quando chegar lá, o lugar é dele. Ele não será rejeitado. E aprendemos muito nesses dez anos.

\section{Como se chama?}

A unidade de medicina paliativa do Inca é o HC IV, em Vila Isabel. O novo programa, projeto da Fundação a ser iniciado neste ano, é chamado nos países de língua inglesa de Hospice, nome de origem latina que significa acolhida, hospedagem. O termo remonta aos antigos estabelecimentos que acol hiam viajantes, em suas jornadas, em busca de um lugar melhor para viver. E no caminho havia sempre alguém que oferecia comida, lugar para dormir por uma noite e, por que não, certa dose de conforto, carinho.

Vocêestá falando dediversas ações, em quehoje a atuação do Inca écentral: hospices, voluntariado... O Inca tem essa característica, de uma atuação mais humanizada, mais integrada à comunidade. Você poderia falar um pouco sobre isso, de uma forma mais geral? Do voluntariado, por exemplo, que é um aspecto importante.

Acreditamos que a humanidade hoje está muito egoísta, não pensa no próximo. E isso é o maior engano. A humanidade tem um potencial enorme de doar ao próximo alguma coisa. Ela precisa ser estimulada a isso e acreditar que essa ação é gratificante. Temos um hotel, por exemplo, em parceria com a empresa McDonald's, que tem as casas Ronald McDonald's no mundo inteiro. São 65 apartamentos, em que qualquer um de nós se hospeda com relativo conforto. Neles a criança pode ficar com a mãe ou com o pai, durante o tratamento de quimioterapia ou de radioterapia. Esse hotel deve ter em torno de 400 funcionários. Só um recebe remuneração, queéo gerente. Todos o outros são voluntários. Nós instituímos uma maneira de lidar com voluntários, porque ser voluntário é ótimo, é maravilhoso, mas ele tem obrigações, como qualquer outro funcionário. Se faltar ao plantão, ele é demitido ou advertido. Porque se faz isso desarma todo o esquema, cuidadosamente montado, dessa forma mais consistente de contribuição voluntária.

Queria dizer que ninguém consegue ampliar o tratamento global de doença crônica, principalmente do câncer, se ele não envolver toda a comunidade. É impossível. Primeiro, 
o voluntariado faz aquilo por paixão. Não é o voluntário que quer aparecer. Embora toda e qual quer doação seja bem-vinda, estamos fal an do daquel e trabal ho de doação continuada. Em todas as instituições do mundo que aproveitam voluntários, os resultados são extremamente superiores em todas as etapas, até no resultado do tratamento. $\mathrm{O}$ crescimento do sistema de saúde no mundo está 'despersonalizando' muito as pessoas. Em vez de ser dona Marta, é uma moça que tem um câncer terminal: "Qual é o nome dela?". "Está na enfermaria 13". Não se sabe se tem filho, se tem mãe, quais são os problemas do dia a dia. Isso tudo é muito importante; não se pode tratar a doença, tem que tratar o indivíduo, com todos os elementos que compõem a personalidade dele.

Vocêacha que o Brasil, por nossa herança ibérica, é deficitário nesse ponto de vista, em comparação, por exemplo, com os Estados Unidos ou a Inglaterra? Somos uma sociedade sensível ao voluntariado?

Há duas maneiras de encarar a questão. A primeira é a doação. Indivíduos que têm fortuna e que doam. Isso ajuda muito. E, então, há o voluntariado, que doa de outra forma, doa trabalho, carinho. Esseéo mais importante. Há pessoas que doam um pouquinho do que podem, ou trabal ho ou pequena parcela do que ganham. Trabal har como voluntário é gratificante. Não há nada mais gratificante para uma pessoa que se doa; não há prêmio maior. E o voluntário ganha mais do que quem dele recebe. É um ganho emocional tão grande...

Como gestor de planejamento de políticas e programas, como você atua para conquistar vol untários?

Começa-se a recrutar voluntários no ambiente familiar das pessoas com câncer e, depois, junto aos amigos. A melhor estratégia é fazer com que eles vivenciem a situação, porque as histórias são mostradas. Há voluntários de todos os tipos. Nas grandes instituições de câncer na Europa, nos Estados Unidos, há voluntários atuando como porteiros do hospital, motorista da ambulância, capelão... O capelão é treinado para dar conforto espiritual, respeitando a crença religiosa, qualquer que ela seja, daquele indivíduo internado e de sua família. Em al gumas comunidades mais desenvolvidas que já têm hospices, respeitam-se até alguns maus hábitos do paciente.

Doutor Marcos, esse programa é enraizado pelo Inca?

Eu não diria enraizado pelo Inca. Há ações de voluntários espalhadas por vários hospitais. Um maravilhoso programa com crianças carentes internadas, no Hospital da Lagoa, é todo feito com voluntários.

Olha só como a humanidade é muito mais bonita do que imaginamos: no Quinta D'Or, antigo hospital São Francisco de Paula, trabal hava um casal, e a moça era acadêmica de medicina do Souza Aguiar. Havia muito chamado da Vila Mimosa, e ela ia atender às prostitutas nas emergências. Lidando então com aquele grupo tão desprovido de qualquer respeito, ela, com pena, se comprometeu a realizar consultas naquele local uma tarde por semana. Ela e o marido acabaram criando um ambulatório nesse hospital, para atender a moradores de rua, prostitutas e al coólatras - eles não têm direito a adoecer; cheiram a urina, estão sujos. Era um trabal ho maravilhoso. Eu não sei o que aconteceu com esse ambulatório. 
Nós os ajudamos na época, mas perdi o contato. Acredito, porém, que podemos encontrar voluntários em tudo quanto é lugar.

Trabalhar como voluntário, para aqueles que têm condições para isso, pode ser muito bom. Agora é meu foco: começamos a fazer o primeiro hospice. Vai ser em um terreno bonito, com reserva de mata original. E tem que ser um lugar bonito, arborizado e com flores. Não se pode colocar o sujeito que está no fim da vida em um quarto escuro, em um lugar que ele não veja o céu. Uma cliente minha fez a doação de parte dos recursosnecessários para sua implantação, e esse será o primeiro núcleo.

Você está apostando mais nisso do que nas políticas de Estado?

Não; considero as duas importantes.

E como você está vendo essas políticas de Estado?

Nesse momento, em relação ao Inca, ao Ministério da Saúde, à nossa Fundação, temos uma situação ímpar. O ministro foi diretor do Inca; quem toca a Fundação deles foi diretor do Inca também, e o atual diretor é muito ligado a tudo isso. É muito difícil ocorrer uma conjunção assim. Entretanto, o financiamento para a saúde no Brasil ainda é muito precário. Quando a parte de saúde do Inamps passou para o Ministério da Saúde, infelizmente os recursos não vieram junto. Depois, o Adib Jatene criou a CPMF, uma forma de se ter um dinheiro destinado ao Ministério da Saúde, ainda muito precário. Se a CPMF não tivesse caído, o Ministério poderia arrecadar o dobro do que recebe hoje. E tem a relação entre a qualidade da política e o potencial econômico para manter aquela qualidade de atendimento. A concepção do Sistema Único de Saúde é maravilhosa, mas ele não tem financiamento adequado para executá-la.

Você está falando sobre saúde pública. Gostaríamos que abordasse sua passagem pelo Inca, onde ficou conhecido como a pessoa que reorganizou a instituição depois de um período de crise. E quando você saiu, principalmente depois da criação da Fundação do Câncer (antiga Fundação Ary Frauzino Para Pesquisa e Controle do Câncer - FAF), o Inca estava em situação financeira e administrativa muito melhor. Além disso, passou a ser o gestor da política sobre o câncer no Brasil.

Eu não tinha nenhuma relação com política. Sou cirurgião, com formação em cirurgia de câncer. Então um conterrâneo me ligou e disse: "O presidente da República mandou convidá-lo para escrever o programa de câncer do próximo governo". Eu nunca o encontrara, a não ser na campanha. Mas, tendo votado ou não, considero obrigação cívica participar disso. Então, em dois meses reunimos uma equipe pequena para avaliar o problema do câncer no Brasil.

Primeiro, vimos que o Instituto Nacional do Câncer tinha esse nome, mas era um hospital na Praça da Cruz Vermelha e não tinha nenhum papel nacional. E a ideia foi: por que não transformá-lo no Instituto Nacional do Câncer? Foi um desafio enorme. Primeiro, mudar a estrutura do Ministério para reconhecer que a política de câncer deveria ser feita pelo Inca. E, depois, enfrentar as dificuldades de uma transformação de estrutura. Não havia organização no Ministério da Saúde que reconhecesse isso. Não existiam os cargos. Só para você ter 
uma ideia, o diretor do Instituto Nacional do Câncer na época tinha um DAS2, o que significa pertencer ao quinto escalão do Ministério da Saúde. O primeiro ponto foi pensar a necessidade de ter uma estrutura. Depois, como suprir o Instituto - então um hospital público carente - com estrutura física e funcional que pudesse atender a essa demanda. Então surgiu a ideia de criar uma fundação de apoio que pudesse suprir essas necessidades. Foi muito difícil, mas me parece que a grande modificação do Inca ocorreu entre as pessoas. Naquela época, o governo estabeleceu um projeto de qualidade administrativa, com foco em uma administração voltada para a qualidade, para os resultados. Existiam três instituições no Brasil que eram reconhecidas por esse programa. Uma fundação em São Paulo, uma em Belo Horizonte e um instituto aqui no Rio, que cuida da qualidade da indústria nuclear, o Instituto Brasileiro da Qualidade Nuclear (IBQN). E o governo instituiu um financiamento para que as instituições se candidatassem. Então, imaginamos um projeto de administração por qualidade. Nós e o Inmetro ganhamos. Começamos a treinar os funcionários, sem nada Ihes prometer, o que, aliás, nem poderíamos, porque nada tínhamos. O objetivo era treinálos para que fossem respeitados e, depois, aprendessem a respeitar o local de trabal ho. Ser respeitado no sentido de ser reconhecido, ter seu mérito no trabalho; que eles participassem do sucesso, que eles fossem informados corretamente de tudo que se passava na instituição. Voltassem a ter orgulho de trabalhar naquele lugar.

Isso era uma ação do governo?

Não; o programa de qualidade administrativa era estimulado pelo governo para treinar as pessoas, a fim de transformar as entidades em instituições de qualidade. E várias empresas do mundo todo já faziam isso. No Japão, por exemplo: a indústria japonesa cresceu exatamente por isso, focando no indivíduo, no funcionário. Não adianta ter uma casa boa, cheia de máquinas, se quem trabal ha não está estimulado. E o diagnóstico mostrou uma coisa interessantíssima. Os funcionários faziam um curso de 16 horas, um curso médico, de qualidade administrativa, e depois disso respondiam a um questionário com vários itens. Um que chamou muita atenção: "O que você acha mais importante para se ver bem em seu trabalho?". O item salário só apareceu em quinto lugar. Primeiro, eles queriam trabal har em um lugar em que as pessoas soubessem quem eles eram. Segundo, ter certeza de que seu trabal ho servia para al guma coisa. E por aí vai. Então, começamos a desenvolver um programa que premiava os funcionários com o que podíamos. Por exemplo, um sujeito que se destacava em seu posto era chamado para tomar café da manhã e recebia um diploma. Mudar a roupa, dar um uniforme mais bonito para o trabalho. Uma série de pequenas ações que, realmente, em um ano, um ano e meio, mudou a instituição. Foi muito duro no começo. E veio a Fundação junto, e havia quem dissesse: "Esse cara criou a Fundação para vender o Instituto às companhias de seguro saúde". Naquela época, o Instituto tinha greve quase toda a semana. Comecei a frequentar a assembleia geral. Chamavam-me: "Diretor, venha fazer parte da mesa". Eu dizia: "Não; sou funcionário como você". Assim fui quebrando um mito. Quando se está presente, não se fala nenhuma inverdade. Então, todos os dirigentes foram preparados e incumbidos disso. Depois começamos a obter resultados, aproveitando as ideias dos funcionários. Vou dar dois 
exemplos, bem importantes, de como ouvir aquele funcionário que está trabalhando ali há 10, 15 anos e aproveitar a experiência dele para fazer mudanças. $O$ almoxarifado compra uma caixa com cinco mil seringas. Não dá para contar, porque 50, 100 caixas são entregues em um dia. Umas vêm com 890, outras com 700; nunca vem tudo. Veja a ideia do funcionário: reunir várias caixas e pesá-las. Assim, teríamos um peso médio. Depois, contaríamos as seringas das caixas que estivessem fora do peso médio. Com isso, tivemos uma economia enorme. E foi ideia de um funcionário. Outro exemplo: usamos muito cateter para a quimioterapia - coloca-se aquilo sob a pele e vê se está pegando a veia, e é necessário mudar toda hora para a comodidade do paciente. E aquilo demorava a ser entregue, e demorava mais ainda até liberar para chegar na unidade de quimioterapia. E quem cuidava da compra nem sabia para que servia. Então, chamamos aqueles funcionários para olhar o que compravam: "Olha, isso aqui salva uma vida; quanto mais ágeis vocês forem, mais vidas serão salvas". Sem punir, sem nada, só dando conhecimento a eles da importância do trabal ho realizado na cura do indivíduo. Eles nunca imaginaram que, com o trabal ho deles, pudessem salvar uma vida. Foi esse ambiente que mudou a instituição, envolvendo as pessoas no trabalho. Qualquer indivíduo, em qualquer área de atuação, é responsável pelo resultado final da instituição como um todo. Se você conseguir mostrar isso, terá como resultado muito pouca gente trabal hando com o pé no freio. Vai ter muita gente trabalhando no acelerador, até acelerando demais. Isso realmente é uma grande mudança de atitude.

E esse trabalho com a iniciativa privada, com a Avon, o McDonald's? Como é esse em que as mulheres da Avon vão de casa em casa, apresentando informações?

Essa é uma instituição que tem milhares de mulheres que visitam casas e são grandes divulgadoras de ações de saúde, mostran do a importância dos exames periódicos. Treinamos também essas mulheres; não podemos treinar todas, mas é muito gratificante. As outras empresas que auxiliam de al guma forma são importantes também.

O problema do doador é que, no Brasil, ele não tem incentivos iguais aos de outros países, a renúncia fiscal. A renúncia fiscal, nos outros países, estimula a doação para uma finalidade, para uma instituição não lucrativa. Museus, bibliotecas, hospitais, institutos de pesquisa, universidades no mundo todo têm grande parceria com o público. Imagina se a Universidade Federal do Rio de Janeiro, a Fundação Oswaldo Cruz... se recrutássemos os ex-alunos. Tem muito ex-aluno ocupando posições top na indústria, no comércio, nas instituições de pesquisa. É preciso ver esses ex-alunos doadores de seu trabalho, de sua renda. Assim é com grande parte do orçamento das grandes universidades do mundo todo, Harvard, Chicago, a Universidade de Londres.

E tem uma história de tradição, não é? Países como Estados Unidos e Inglaterra têm tradição nisso, nós não.

Nós só temos 500 anos. Temos muito tempo pela frente. A Europa tem mais de 2.000. Mas acho que estamos amadurecendo nesse sentido. Nós vivemos duas coisas completamente separadas: o público e o privado. Nem tudo o que é privado é ruim. E nem tudo o que é público é o melhor. Então, temos que chegar em uma zona fronteiriça, em que ambos se 
possam beneficiar muito. A parceria público-privado é muito importante e é vitoriosa no mundo todo. O que não se pode é fazer do ensino, por exemplo, algo lucrativo. Você até pode lucrar com o ensino, mas não pode fazer uma universidade apenas para lucrar. Uma universidade pode ser privada, e a maioria das universidades privadas no mundo é até melhor, mas com um grande auxílio do governo. Harvard, Boston e a Universidade de Chicago são universidades privadas com grande intercomunicação com o governo, com programas de continuidade. Não há nenhuma finalidade lucrativa. Ninguém coloca dinheiro no bolso.

\section{E a ação da filantropia?}

Essa é uma cultura que precisa ser mais desenvolvida. Para se ter uma ideia, há alguns anos, encomendamos ao Ibope uma pesquisa para conhecer o potencial de doadores no Grande Rio. Por exemplo, estamos precisando de um laboratório de biogenética, que vai custar R $\$ 10$ milhões. Um grande doador, uma empresa, pode dar esse valor. E depois? Como vamos manter isso? O que permite a uma instituição não lucrativa se manter é o pequeno doador, é aquele que dá pouquinho sempre. Então, o objetivo dessa pesquisa foi saber o que aconteceria, no Rio de Janeiro, se organizássemos um programa de captação de recursos, de tal forma que convencesse cada pessoa a doar $\mathrm{R} \$ 1,00$ por mês. Encontramos algumas coisas muito interessantes. Primeiro, palavras mágicas para doação, em relação a nosso horizonte de doença: câncer e criança são palavras absolutamente mágicas. Abrem portas; tocam o doador brasileiro, governo, pessoas físicas, jurídicas. Isso foi feito da classe A à classe D. E encontramos na classe socioeconômica mais baixa um grande número de indivíduos que estão dispostos a doar. Outro grande problema do doador no Brasil é que, em vez de doar para uma ação continuada, sobre a qual tem conhecimento, ele dá uma esmola. E nunca tem informação sobre o dinheiro dele, o que foi feito, o que aquela doação resultou em termos de benefício para a sociedade. Então, nesse aspecto temos uma norma. Se você doar $R \$ 50,00$, vai ser informado do que foi feito daquele dinheiro, em que ação foi utilizado.

A primeira tentativa que fizemos foi há cinco anos. O ex-embaixador da Irlanda no Brasil era um fund raiser, uma pessoa que, em outros países, tem formação universitária como arrecadadora de recursos. No início de sua carreira profissional foi captador de fundos para a Universidade de Londres. Nós o trouxemos para trabalhar conosco. Mas a cabeça dele era a de quem fala com alguém que dispõe de incentivos fiscais. A instituição ainda não estava preparada para isso. Porque se você tem uma fundação de apoio, deve abdicar de ter sua imagem em primeiro plano e dar ênfase à imagem das instituições doadoras. Costuma ser muito difícil, para a instituição que recebe, aceitar isso. Acha que é perda de prestígio. Uma série de mudanças na cultura da doação precisa ser entendida, absorvida. $\mathrm{O}$ que é importante para quem doa? Que o dinheiro dele seja utilizado no que ele pensou, adequadamente para melhorar, por exemplo, algum setor da Fundação Oswaldo Cruz, algum laboratório da Universidade Federal do Rio de Janeiro, al gum programa do Instituto Nacional do Câncer? Para isso é preciso que tanto quem arrecada como quem recebe esteja preparado. No Brasil ainda vai demorar algum tempo para se ter uma política de doação 
continuada. Alguns programas fazem muito sucesso durante determinado tempo e morrem. Morrem por quê? Por isso, pela falta de informação ao doador. O doador tem que ser informado como se ele fizesse um depósito bancário. Sua 'conta' com a instituição que recebe seus recursos deve conter todas as informações sobre a aplicação daqueles recursos. Isso é algo fundamental para se manter o doador vinculado ao programa.

Isso vale tanto para o pequeno como para o grande doador?

Para qualquer um. O cara que dá $R \$ 2,00$ ou $R \$ 1,00$ na conta de luz. Da mesma forma que você pede na conta de luz, você informa na conta de luz. Tem o exemplo do Memorial Sloan Kettering Cancer Center, em Nova York, aparentemente difícil de entendermos no Brasil. O Memorial é o melhor hospital de câncer do mundo, instituição filantrópica e não lucrativa, que arrecadava pouquíssimo junto ao público. Recebia muita doação de milionários. Há uns 10, 15 anos, resolveu fazer um programa de captação de recursos com o pequeno doador. Chamaram a empresa mais poderosa de captação de recursos nos Estados Unidos e disseram: “Queríamos que vocês desenvolvessem um programa de captação de recursos. Um programa muito bem elaborado, para ser apresentado ao Conselho de Curadores". Na primeira reunião, eles quase foram enxotados, porque cobravam 39\% do que era captado. Mas nesses $39 \%$ estava incluído tudo, todo o custo do programa. Começava assim: avaliar toda a população americana para ver quanto poderia ser doado; as pessoas que tinham herança e não tinham herdeiros; as pessoas que podiam doar uma pequena quantia. Dois anos depois, eles recebiam doações mensais de 1,5 milhão de americanos.

Você está sugerindo que essa área ainda é pouco profissionalizada, ao contrário do que acontece na área da cultura, em que hoje em dia há até faculdade que ensina captação cultural?

A profissionalização aqui ainda é zero. Nos países desenvolvidos, existe uma carreira com formação universitária. As possibilidades da captação para a cultura via lei Rouanet não se aplicam à saúde.

Eu também acho que o sistema anterior, em que os grupos de trabal hadores tinham seu futuro de previdência e assistência médica organizados separadamente, facilitava a criação de uma identidade. Quando cresceu e virou Inamps, despersonalizou. Se você era bancário, ia ser atendido no próprio ambulatório dos bancários. Passou a ser de todo mundo. E como o que é de todo mundo não é cuidado, passa a ser de ninguém. Então, perdeu-se aquela identidade, como se está perdendo hoje a identidade com o médico. Se você vai um dia em um consultório, outro dia em outro, outro dia num terceiro, com qual você terá uma relação mais próxima? Por isso é importante o programa Médico de Família, que é o grande sucesso de Cuba com relação à mortalidade infantil. Cuba é um país pobre, com grandes problemas econômicos, mas saúde e educação são modelos exportados. É marca do país. Não se pode imaginar um país como Cuba, com mortalidade infantil igual à de países desenvolvidos.

Você está expressando muito interesse nas questões de saúde pública. Como foi, para uma pessoa que tem esse interesse em saúde pública, gerir uma instituição como o Inca, que por um lado tem um 
grande número de profissionais voltados para esse polo e, por outro, tem vários profissionais mais voltados para a alta complexidade, para cirurgias de alto custo. Houve embate? Como foi essa gestão?

A alta complexidade vai dos medicamentos mais caros até o abuso e desperdício de descartáveis. Com todo o recurso que se tem, com toda a qualidade dos exames de imagens, dos exames de laboratório, nada substitui uma boa entrevista e um bom exame médico. Infelizmente, são poucos os quefazem isso hoje. Um consultório mal equipado, sem otoscópio para ol har o ouvido, sem oftalmoscópio, sem aparelho de pressão, não dá conta. Na periferia, a dificuldade material de coisas pequenas é muito grande. Às vezes, veem-se paradoxos: uma unidade de saúde com esse tipo de problemas está querendo um aparelho de ressonância magnética. Um otoscópio ou um oftalmoscópio seria muito mais útil à maioria das pessoas que procuram o hospital do que uma ressonância magnética, paradigma de alto tratamento, alta qualidade de saúde. Mas isso existe. É muito difícil lidar com a medicina de alta complexidade, transplantes, exames sofisticados, terapias-alvo, anticorpos monoclonais, pesquisa. Outra questão, que é muito difícil para o administrador de saúde entender, é a importância da pesquisa. A maioria da coletividade científica, médica, ou de outro setor médico, acredita que pesquisa é algo feito por sujeitos esquisitos que ficam dentro do laboratório, sem que ninguém saiba o que estão fazendo. E aquilo resulta em quê? Depois publicam um trabalhinho. Há oito anos, uma fundação americana resolveu contratar as cinco universidades mais importantes do país. Suas faculdades de economia deveriam fazer um estudo para informar o valor econômico da pesquisa, quanto a pesquisa resulta em economia. Um trabal ho interessante, que todo administrador de saúde, todo ministro deveria ler. Resultado: economizou-se muito com a pesquisa de desenvolvimento de diagnósticos mais eficientes, remédios para hipertensão, redução da mortalidade por doenças cardiovasculares, $40 \%$ nos últimos 40 anos. Quais são os valores disso? São bilhões e bilhões de dólares por ano. E nasceram de pesquisas de laboratórios.

Em sua avaliação, como é o cenário da pesquisa de saúde no Brasil?

Como o cenário da pesquisa no Brasil de um modo geral. O atual presidente da Capes, Jorge Guimarães, pesquisador de bancada, modificou completamente a pesquisa no Brasil, entre outros aspectos dando ferramentas ao pesquisador, como o Portal Capes, em que o pesquisador tem acesso a todas as revistas importantes do mundo na casa dele. Isso é de uma visão! O Brasil hoje ocupa o $12^{\circ}$ Iugar em publicações científicas. Acima da Suíça, por exemplo. Quer dizer, a Capes e o CNPq, nestes últimos dez anos, fizeram uma transformação sensacional e acenam com um resultado bastante promissor em pesquisa no Brasil. Eu dirijo, na Universidade Federal do Rio de Janeiro, o Programa de Oncobiologia, que congrega pesquisa em câncer na UFR, Uerj, Inca, UFF e Cefet. E eu nunca tinha trabalhado diretamente com pesquisadores. É uma surpresa muito gratificante, por um lado, e muito triste, por outro. Os grandes pesquisadores trabal ham em condições precaríssimas: uma pia que cai toda hora, uma luz que não acende, uma privada que não funciona, uma luz do microscópio que quando queima demora dois meses para orçar e chegar uma lampadazinha. Coisas assim, que se pode mudar completamente com uma medida pequena, até Quem sabe, fazendo uma doação pequena para cada pesquisador, para as coisas do dia a 
dia dele, além do que ele recebe. Assim, consegue-se modificar completamente a produção da pesquisa, com esse incentivo. Você perde, às vezes, algo importante: você está fazendo uma pesquisa, e o reagente acabou, e você tem que comprar naquele dia, porque os animais têm de tomar naquele dia. E acaba, porque não tem nenhum mecanismo ágil de compra. Mas o Brasil tem excelentes pesquisadores. Hoje nosso programa tem cerca de 30 linhas de pesquisa e mais ou menos 300 pesquisadores.

Como você está vendo a prática e a formação de novos oncologistas?

Há poucas instituições, no Brasil, capazes de formar novos oncologistas, muito poucas; são 31 hospitais filantrópicos de câncer, dos quais os de pesquisa são meia dúzia. Quer dizer, pesquisa pesada em câncer existe em algumas universidades. Nós temos instituição de câncer aqui, o Hospital Antônio Prudente, em São Paulo, o Hospital de Clínicas de Porto Alegre, que tem setor de câncer, e a Santa Casa de Porto Alegre, outro exemplo no Brasil: um programa de qualidade mudou completamente sua estrutura; é hoje o hospital mais bem administrado do país, o maior transplantador de pulmão, fígado, rim da América Latina, graças a um programa de qualidade, envolvendo a comunidade.

O segredo é investir nas pessoas. Se tiver gente entusiasmada, de qualidade, trabal hando em um barracão na Universidade, você tem como fazer. É esse o foco que os políticos precisam descobrir: trabalhar com as pessoas. As outras coisas são secundárias. As pessoas são fundamentais, quando estimuladas. Você não precisa ser piegas, bonzinho. Você tem que exercer a autoridade, fazer com que as pessoas participem das conquistas, façam parte da instituição, se sintam parte dela. O que adianta você mandar o cara assinar o ponto? Assinar o ponto e ficar o dia todo na empresa sem fazer nada é fácil. Você tem que cobrar resultados. Tem que estimular, porque o resultado é uma das conquistas. Quantas pessoas aposentadas, com mais de 50, 60 anos de idade, estão em casa se sentindo inúteis e dariam a vida para trabalhar em uma instituição como a de Porto Alegre, sem ganhar nada? Muitas. Só para serem respeitadas e terem um trabalho do qual se orgulhar.

Como você levou a experiência que teve no Inca para a sua gestão na Academia Nacional de Medicina, que se encerrou em jul ho de 2009? Como essas coisas se aproximam?

A gestão das instituições é muito parecida. Gerir a Academia Nacional de Medicina, instituição que congrega teoricamente os 100 mais afamados médicos do país, não édiferente de gerir uma instituição de ponta. Tem que ter métodos administrativos parecidos. Nesse sentido, tem que ter uma meta de trabal ho, não pode apenas sentar na cadeira de presidente da Academia Nacional de Medicina. Para a carreira do médico, é um cargo de reconhe cimento top. Mas o que significa isso, se vocênão faz nada, só senta na cadeira de presidente? Nada. Tem muito trabalho, muito trabalho. Isto já foi dito várias vezes: se você tiver um trabalho muito importante para fazer, nunca procure uma pessoa que não está muito ocupada. Sempre, quanto mais ocupado for o sujeito, mel hor fará o trabalho. O desocupado vai continuar desocupado do mesmo jeito. 
Os hospices e os programas de voluntariado para o câncer

Ficha técnica:

Data: outubro de 2009.

Local: Fundação do Câncer, Rio de Janeiro.

Entrevistado: Marcos Fernando de Oliveira Moraes.

Entrevistadores: Claudia Jurberg, Jaime Larry Benchimol, Luiz Antonio Teixeira, Ruth B. Martins.

Transcrição de fitas: Clarice Tenório.

Edição: Luiz Antônio Teixeira, Ruth B. Martins.

Revisão técnica: Claudia Jurberg. 